\title{
Una ventana sobre la sociedad decimonónica: los periódicos católicos, 1845-1857*
}

Erika Pani

EL COLEGIO dE MÉXICO

\begin{abstract}
Se examina, a través de la prensa católica, cómo ciertos grupos conservadores perciben a la sociedad mexicana, a la religión y al Estado entre 1845 y 1857.
\end{abstract}

¿Quiera el cielo que reconocida y acatada la religión, sea ella el primero y más poderoso elemento de vida que regenere nuestra moribunda sociedad!

La Cruz, 14 agosto 1856

$\mathrm{L}$

a lucha por el poder político en el México decimonónico, hasta el triunfo liberal de la república restaurada en 1867 , ha sido caracterizada por la historiografia como la pug

* Agradezco a la doctora Anne Staples y a mis compañeros del seminario Cultura y Sociedad en el siglo XIX sus comentarios y sugerencias. na entre dos ideologías rivales, dos proyectos de nación encontrados: el liberal y el conservador. Los partidarios de estas dos visiones diferentes, llámense yorkinos y escoceses, federalistas y centralistas, o liberales y conservadores, aparecen como los protagonistas principales de la historia política del siglo XIX mexicano. A menudo, los liberales aparecen como hombres de su tiempo, campeones de la libertad, la democracia y el progreso, que pretendian sacar a México del arcaísmo, la pobreza y la inestabilidad en que se hallaba sumido. A su vez, los conservadores son descritos como el 
elemento retrógrado de la sociedad mexicana por su falta de visión y por afanarse en conservar las instituciones y privilegios anquilosados, heredados de la época colonial, que los llevó incluso a apoyar el imperio de un príncipe austriaco, sostenido por ejércitos franceses... Ya en 1868, José María Iglesias escribía, sentando el tono de la historiografia posterior, que los conservadores merecían "a la vez de la de traidores, la calificación de imbéciles". 1

Es deber del historiador romper con ese esquema simplista de héroes y villanos. La biografia de un personaje como Antonio Haro y Tamariz muestra que las líneas divisorias entre liberales y conservadores no fueron tan tajantes y que el grupo conservador no fue hermético, agazapado sobre sus sueños de gloria virreinal, ciego a toda propuesta novedosa. ${ }^{2}$ Los conservadores representaron, durante gran parte del siglo XIX, una alternativa politica y social importante, y la comprensión de este siglo se empobrece si se les descarta simplemente como el elemento reaccionario que impedía que los liberales impulsaran el desarrollo del país. En este sentido, es interesante comparar, por ejemplo, algunos proyectos de desarrollo económico "liberales" y "conservadores". Para un liberal como José María Luis Mora, la prosperidad del país debía fincarse no en una "industria forzada", ${ }^{3}$ sino en la repartición más o menos equitativa de

${ }^{1}$ Iglesias, Revistas, 1868, vol. 2, p. 322.

${ }^{2}$ Bazant, Antonio, 1985.

-3 José Ma. Luis Mora, citado en Hale, Alamán, 1961, p. 227. la propiedad rural, pues eran "las pequeñas y productivas propiedades habitadas por el dueño [...las que hacían] el bienestar de los habitantes de un país". ${ }^{4}$ Por su lado, Lucas Alamán promovía - a través de instrumentos que hoy nos parecen tan familiares, como la protección arancelaria y el financiamiento público de inversionistas nacionales a través del Banco de Avío, fundado en 1830-el desarrollo de una industria moderna, apoyada por el Estado, que aseguraría el bienestar del país, impidiendo que México se viera reducido a un "colonialismo económico" ${ }^{5}$ El proyecto un tanto bucólico de Mora, con su visión de prósperos granjeros individualistas, era quizá más atinado que el de Alamán, en un país tan rural como el México decimonónico. ${ }^{6}$ Sin embargo, el proyecto de industrialización del "patriarca" de los conservadores ${ }^{7}$ puede sin duda calificarse de progresista, y quizá iba más a tono con los impulsos modernizadores más dinámicos de la época, tanto en Europa (sobre todo en Inglaterra) como en Estados Unidos. ${ }^{8}$

Con miras a profundizar el conocimiento acerca de los conservadores,

${ }^{4}$ Mora, Clero, 1950, pp. 157-158.

5 Hale, Alamán, 1961, pp. 233-234, p. 237.

${ }^{6}$ Cabe hacer notar que, en general, Mora tendía a dar mayor énfasis a la vida urbana, ignorando importantes aspectos de la realidad rural. Lira, Espejo, 1984, p. 71.

${ }^{7}$ Cabe destacar que este proyecto lo defendían, además de periódicos conservadores como El Universal, El Orden y El Ómnibus (después de 1848), la publicación liberal El Siglo XIX, y un hombre como Esteban de Antuñano, primero conservador y luego liberal. Hale, Alamán, 1961, p. 238, p. 240.

${ }^{8}$ Hale, Alamán, 1961, p. 224. 
se examinará en este trabajo la posición de un grupo de conservadores católicos en la década que precedió a la guerra de Reforma. Se trata, pensamos, de una época especialmente interesante, pues durante estos años presenciamos una creciente polarización ideológica, y el progresivo endurecimiento y radicalización de ciertos grupos. Durante los primeros veinte o treinta años de vida independiente, la clase política mexicana marchaba un poco "a la deriva": 9 ni principios politicos, ni proyectos de nación, ni grupos de poder acababan de cuajar. Esta falta de definición implicaba cierta flexibilidad de negociación, cierto espacio de maniobra. Por ejemplo, la Constitución de 1836, que se supone la obra cumbre del conservadurismo en el poder, ${ }^{10}$ representa, como ha demostrado Reynaldo Sordo, un verdadero "documento compromiso" entre tendencias centralistas y federalistas, no sólo porque federalistas y moderados participaron en su elaboración, sino porque los supuestos "conservadores triunfantes" eran en realidad hombres "atrapados" entre sus principios conservadores e intereses de grupo y "las ideas del siglo": liberalismo, republicanismo, derechos del hombre, etc. ${ }^{11}$ Si bien existian diferentes tendencias ideológicas que se

9 La expresión es de Alfonso Noriega. Noriega, Pensamiento, 1972, vol. II, p. 351 .

${ }^{10}$ Ibid., vol. I, p. 106.

11 Sordo, Congreso, 1993, p. 419. También durante las sesiones del fracasado Congreso de 1842 , se intentó conciliar las tendencias federalistas y centralistas. Noriega, Pensamiento, 1972 , vol. II, p. 342 . consolidarían progresivamente, el enfrentamiento violento entre el "partido del progreso" y el del "retroceso," que según Mora antecede a la independencia, ${ }^{12}$ es quizá más un producto conveniente de la historiografía liberal que un reflejo fiel de la realidad. ${ }^{13}$ En este sentido, es ilustrativa la descripción que hizo Alamán del partido "puro", ya en 1850: "Franco y decidido, generoso a veces y magnánimo, emite sus ideas con resolución y energía y bien se conoce en su atrevida actitud que tiene fe en su sistema". ${ }^{14}$ Como vemos, este retrato estaba lejos de implicar un odio feroz hacia el enemigo acérrimo.

$\mathrm{Al}$ analizar, aunque superficialmente, el ideario de los hombres públicos de las primeras décadas de vida independiente, podemos decir, siguiendo a Edmundo O'Gorman, que éstos intentaban definir a la nación, establecer su identidad, decidir cómo debía ser México. ${ }^{15}$ Los proyectos liberal y conservador de nación postulaban, a fin de cuentas, lo mismo: hacerse de una prosperidad como la de Estados Unidos pero sin abandonar el modo de ser tradicional hispano y criollo, heredado de la época colonial. ${ }^{16} \mathrm{La}$ lucha entre liberales y conservadores se traducía entonces esencialmente en un conflicto de medios y prioridades,

12 "Revista política de las diversas administraciones que la República Mexicana ha tenido hasta 1837," en Mora, Obras, 1986, vol. 2, pp. 295-298.

${ }^{13}$ Hale, Mexican, 1968, p. 116.

${ }^{14}$ El Universal, 20 agosto 1850 , citado en Noriega, Pensamiento, 1972, vol. 1, p. 93.

15 O'Gorman, México, 1977, pp. XI-XIl.

16 Ibid., p. 33. 
generalizando burdamente, con los liberales dando prioridad a la "modernidad" y los conservadores a la conservación de un orden de cosas tradicional (dentro del cual, como veremos, Iglesia y religión desempeñaban un papel central). Quizá pudiéramos leer los esfuerzos de conciliación de intereses - a pesar de la creciente polarización ideológica y del desorden social endémico- llevados a cabo durante los primeros 20 años de vida independiente como esfuerzos por alcanzar esta visión hegemónica de México como nación independiente.

Sin embargo, las cosas cambian durante la década que pretendemos analizar. ¿Cómo desemboca la situación en una guerra civil entre dos bandos intransigentes, que sólo se resolverá definitivamente con la derrota total de uno de los contingentes? Ya desde los primeros años de la década de los cincuenta $-\mathrm{y}$ pensamos que el impacto psicológico de la invasión norteamericana representó una pieza clave dentro de esta transformación, aunque un estudio detallado de éste queda fuera del presente trabajo- ciertos grupos empezaron a consolidarse y a concretar lo que percibían principios políticos y sociales propios, que tenían que defender frente a otros grupos, que ahora consideraban enemigos. Así, ciertos proyectos de nación -notablemente los llamados "liberal puro" y "conservador" - fueron considerados entonces totalmente excluyentes uno del otro, como lo ilustran las palabras de Lucas Alamán al explicar las motivaciones de aquellos que se definirían, de ahi en adelante, como "conservadores:"
Nosotros nos llamamos conservadores [...] porque queremos primeramente conservar la débil vida que le queda a esta pobre sociedad, a quien habeis herido de muerte [...] Nosotros somos conservadores porque no queremos que siga adelante el despojo que hicisteis; despojasteis a nuestra patria de su nacionalidad, de sus virtudes, de sus riquezas, de su valor, de su fuerza, de sus esperanzas [...] Nosotros queremos devolvérselas; por eso somos conservadores. ${ }^{17}$

Nos interesa descubrir cómo se llegó a tal grado de resentimiento y de recriminación. Nos hemos concentrado en el análisis de ciertos grupos de conservadores católicos, por la importancia que adquiriría-loveremosla cuestión religiosa en el debate politico de esos años. ${ }^{18}$ No se trata aquí de revisar exclusivamente la posición política de este grupo a través de los escritos de sus "ideólogos", sino de desentrañar la "visión del mundo" de esos hombres y mujeres, la manera en que percibían la sociedad mexicana y la situación del país. Para eso, hemos utilizado como fuente principal algunos periódicos católicos de la época.

La prensa mexicana del siglo XIX, además de reflejar las "actitudes vitales" del momento, representa un órgano mediante el cual los grupos de interés difundían su posición. ${ }^{19}$ Aunque esos periódicos católicos no mostraban la opinión de todos los conserva-

${ }^{17}$ El Universal, 22 enero 1850, en Noriega, Pensamiento, 1972 , vol. I, pp. 66-67. 394.

${ }^{18}$ Noriega, Pensamiento, 1972, vol. II, p.

19 Velasco, Guerra, 1975, p. 13. McGowan, Prensa, 1978, p. 14. 
dores ni tampoco la de la Iglesia como institución, difundían la posición de un sector de la sociedad -incluido el sector más importante de la alta jerarquía eclesiástica- cuya actitud será un factor determinante tanto durante la guerra de Reforma como durante la intervención y el segundo imperio. Este grupo, desilusionado de la vida independiente, sintiéndose agredido y percibiendo la inminente destrucción de la sociedad mexicana, formará el núcleo de la resistencia en contra de medidas liberalizadoras (comola desamortización de los bienes del clero y, sobre todo, la libertad de cultos).

Para estudiar las ideas y la visión de este grupo, se ha concentrado la atención en algunos periódicos católicos que ilustran diferentes momentos del periodo que se estudia: $E l$ Católico (publicado entre 1845 y 1847), El Espectador de México (1851-1852), La Verdad Católica(1853-1855) y LaCruz (1855-1857). Cabe mencionar que $E l$ Espectador de México no es un periódico de noticias, sino una revista "de religión, ciencias, literatura y bellas artes," quizá leída por un público más bien femenino o familiar. Aunque el tipo de artículos que publicó (destacan las novelas cortas sentimentales) contrasta con los artículos más "serios" de los otros periódicos (aunque éstos incluyen también secciones literarias), son interesantes porque esas "anécdotas" y "novelitas" ilustran la imagen que nos dan estos periódicos de la sociedad decimonónica, y de los ideales de cierto grupo. Dejando a un lado el tono a veces sensacionalista y melodramático, estos periódicos católicos nos permiten entrever la "cosmovisión" de algunos grupos conservadores. ¿Cómo veían a la sociedad contemporánea? ¿Qué papel debía desempeñar la religión dentro de ésta, y en relación con el Estado? Este trabajo pretende dar respuestas, aunque tentativas, a ambas preguntas, $y$ acercarse a lo que había detrás del grito de "ireligión y fueros!" y del proyecto de nación cuya defensa provocó una de las guerras civiles más cruentas del país.

\section{UNA SOCIEDAD QUE SE DESMORONA}

\author{
Un pais que por una lucha \\ encarnizada y sangrienta de más de \\ treinta años, tiene divididos a sus \\ habitantes con amargos odios y \\ duras preocupaciones. \\ La Verdad Católica, 25 febrero 1854
}

La primera mitad del siglo XIX mexicano se caracterizó por una inestabilidad endémica. Concluida la guerra en contra de España, los gobiernos del México independiente, siempre en bancarrota, se sucedían unos a otros sin lograr establecer, a nivel nacional, una semblanza de cohesión y orden. Proliferaban multitud de proyectos políticos que iban desde el "Plan reformador de Tarecuato", que declaraba a los pueblos "libres de dependiente" y "soberanos" (26 enero 1832), hasta el plan para establecer una monarquía indígena de los curas Carlos Tepisteco Abad y Epigmenio de la Piedra ( 2 febrero 1834), sin que la sociedad mexicana lograra encontrar un sistema de gobierno razonablemente eficaz y estable. ${ }^{20}$

${ }^{20}$ Planes..., 1987, libro 2, p. 82, p. 208. 
En la prensa católica de la época se reflejaba este sentimiento de inseguridad y de frustración. Estos periódicos se declaraban "exclusivamente religiosos", y por lo tanto se suponían apoliticos. En general, no incluían artículos sobre la vida política mexicana si los sucesos no afectaban directamente a la religión. A pesar de eso, abundan los artículos sobre los ataques de indios nómadas en el norte del país, ${ }^{21}$ sobre la inseguridad en los caminos ${ }^{22}$ y sobre la alta criminalidad. ${ }^{23}$ Se percibe la impotencia y el resentimiento de una población que se sentía desamparada, en un país donde "nuestras luces están tan limitadas que no salen del radio de nuestras ciudades", ${ }^{24}$ donde "son [...] demasiado frecuentes los asaltos nocturnos", "mientras [...] la policía duerme, y las autoridades duermen" ${ }^{25} \mathrm{En}$ esos artículos se advierte un rechazo patente a los "nuevos" gobernantes, campeones de principios altisonantes como "libertad" $\mathrm{y}$ "progreso" pero incapaces de imponer el orden:

Los departamentos invadidos por los bárbaros, gimieron largos años víctimas del más incomprensible abando-

21 "Agencia para indemnizar a las familias de los perjuicios causados por los bárbaros", La Verdad Católica, 14 enero 1854. "Doscientos indios en Coahuila", El Católico, 20 septiembre 1845. "Derrota de bárbaros en Durango", "Cuatrocientos comanches en Zacatecas", El Católico, 1 noviembre 1845.

${ }^{22}$ La Verdad Católica, 18 febrero 1854 y 25 marzo 1854.

23 "Horrible atentado", El Católico, 22 noviembre 1845 .

${ }^{24}$ La Verdad Católica, 11 febrero 1854.

25 "Horrible atentado", El Católico, 22 noviembre 1845 . no, cuando nuestros gobernantes pasaban el tiempo a forjar inútiles teorías; $y$ los moradores de aquellas desoladas comarcas perdían diariamente sus vidas y haciendas bajo el hacha del salvaje, mientras que en esta capital y en otras veinte, se proclamaban los derechos y libertades de las víctimas... Vergüenza da recordar aquella época de locuras, mezcla confusa de ridiculeces y de horrores, en que el pueblo se dejó oprimir por unos cuantos ilusos, que no tenían otros títulos a la pública consideración, que la audacia con que proferian cuatro palabras sin sentido, las cuales eran, sin embargo, su única ciencia de gobierno. ${ }^{26}$

Al lado de ese sentimiento de desprecio por esas modernas y poco eficientes formas de gobierno, se percibe cierta añoranza por la estabilidad que reinaba durante la época colonial. Más de 30 años de desorden, inseguridad y conflicto habían frustrado las esperanzas de un futuro brillante para el nuevo país independiente. Los conservadores idealizaban los últimos años del siglo XVIII, durante el gobierno de los Borbón, cuando los levantamientos eran sucesos excepcionales y viajeros y comerciantes podían transitar por los caminos, protegidos por la Acordada, como un oasis de legalidad y de paz. ${ }^{27}$ Los gobiernos del México independiente no habían hecho más que destruir esa estructura estable, que consideraban arcaica, com-

26 "Agencia para indemnizar a las familias de los perjuicios causados por los bárbaros", La Verdad Católica, 14 enero 1854. 465 .

27 Véase Alamán, Historia, 1938, vol. III, p. 


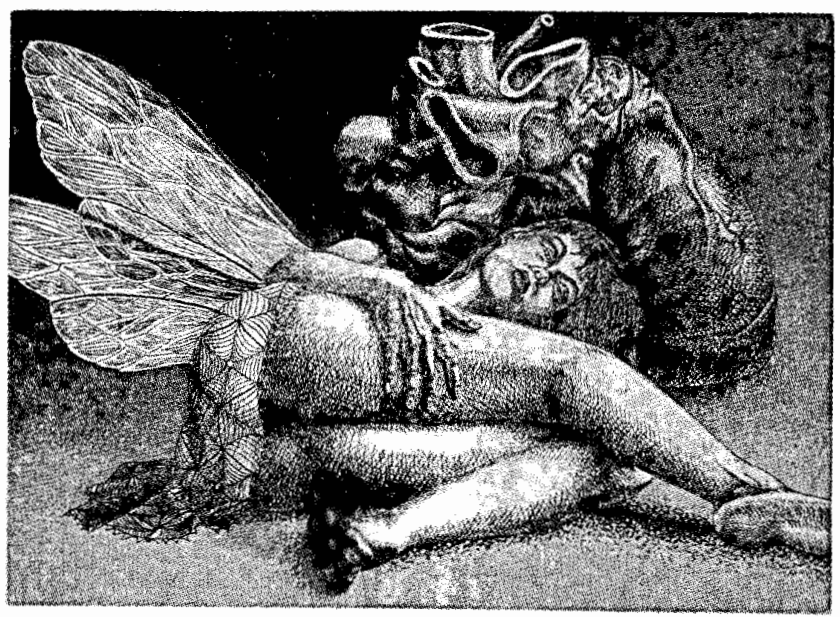

plicada e injusta, sin lograr no obstante reemplazarla:

No eran bastante, sin embargo, para cimentar nuestra felicidad nacional, desde que nos hicimos independientes, tantos desórdenes, ese caos inmenso, ese laberinto de imposible salida, que constituían los códigos, leyes, cédulas, pragmáticas, ordenanzas, autos acordados, bandos gubernativos, constitución, decretos de Cortes, etc., etc. Necesitábamos mayores desaciertos, y a estos se entregaron nuestros legisladores. Sentaron como doctrina incontestable que cuanto existía, fruto de muchos siglos de estudio y experiencia, era inoportuno, añejo y despreciable; y el espíritu innovador llamado con altanería e insolente impropiedad progreso, trabajó tan sólo en destruir todo lo edificado, y sin cuidarse siquiera de separar los escom- bros para cimentar de nuevo, elevaron colosales columnas sobre aquel polvo, incapaz de resistirlas; y edificando siempre sobre ruinas con el firme propósito de cubrir las primitivas, nada sólido hemos hecho en treinta y tres años de existencia política, y entre ruinas nos encontramos, próximos a desaparecer con ellas. ${ }^{28}$

Para los redactores de estos periódicos, así como para las principales figuras del grupo conservador, gran parte de los males del país radicaba en el "espíritu del siglo".29 Los gobernantes del siglo xIX pretendian que "el talento, el genio y las prendas felices

28 La Verdad Católica, 14 enero 1854.

${ }^{29}$ Alamán, Historia, 1938, vol. III, p. 459.

Grabados del Taller Tiempo Extra Editores. Fotografía de Mónica Velasco.

Queda estrictamente prohibida la reproducción total o parcial

de las imágenes publicadas en este número de la revista Secuencia, 36.

Las imágenes fueron contratadas y/o donadas de forma exclusiva para esta publicación. 
del corazón" eran "patrimonio de cierto siglo", y desechaban como "defectuoso y ridículo" todo lo que los había precedido. ${ }^{30} \mathrm{El}$ liberalismo, "mal entendido y peor aplicado", ${ }^{31}$ inspirado en "la impiedad desoladora conocida como la filosofia del siglo XVII", había minado los cimientos de la armonía social mexicana. ${ }^{32}$ La libertad y el individualismo habían roto la jerarquía de la sociedad colonial, y habían desplazado el respeto por la autoridad tanto civil como religiosa: el pueblo había perdido "en mucha parte su sentido moral, sin adquirir por esto espíritu público; [se había desecho] de su antigua subordinación, sin ejercer por esto sus derechos". ${ }^{33}$ El materialismo y el egoísmo habían convertido al dinero en la única distinción, por lo que, se quejaba Lucas Alamán, nadie se sentía "obligado a servir a su país con su fortuna", ${ }^{34}$ o a auxiliar al prójimo. La afición indiscriminada a las novedades, el desprecio total por lo antiguo, las doctrinas "modernas" que habían adoptado los liberales, representaban, a los ojos del grupo conservador, en mayor o menor medida, una fuerza exclusivamente destructora. Era el deber de los periódicos católicos, si no eliminar esta fuerza, por lo menos exponer sus errores: el siglo XIX parecía, afirmaba el prospecto de El Espectador de México,

${ }^{30}$ Clemente de Jesús Munguía, en García Alcaraz, Cuna, 1971, p. 406.

31 Ibid., 1971 , p. 405.

32 "La religión en México", El Espectador de México, 18 enero 1851 .

${ }^{33}$ Munguia, en García Alcaraz, Cuna, 1971, p. 405 .

${ }^{34}$ Alamán, Historia, 1938, vol. III, p. 455. destinado a dar al mundo el espectáculo de todas las revoluciones consumadas, y de todos los desvarios intelectuales puestos en acción, lo está sin duda también para restituir a la razón con sus derechos y a la inteligencia el uso legítimo de sus facultades, haciendo brillar la luz de la verdad olvidada, sobre las densas tinieblas del error, tanto tiempo enaltecido. ${ }^{35}$

Los periódicos católicos reflejaban las actitudes y preocupaciones de ciertos grupos sociales angustiados y resentidos. Por otro lado, la crítica social es menos sutil y más pintoresca en el retrato que hacía de ciertos sectores de la sociedad. La prensa ofrecía la versión, "para consumo público", de la ideología del grupo conservador. Los artículos presentaban una visión esquematizada de la sociedad a través de la cual el lector podía reconocer e identificar fácilmente a "los buenos" y a "los malos". Los dos estereotipos sobre los cuales descansa esta visión de la prensa católica son el del joven y el de la mujer.

El muchacho típico de la prensa católica es

un joven [...] instruido en las ideas de [...] la nueva escuela. Es incapaz de cometer una mala acción y de entusiasmarse por cosa alguna. Su honor no le permitiría robar a nadie un solo centavo, y sus teorías acerca de la sociedad le prohíben dar limosna al pobre andrajo-

${ }^{35}$ El Espectador de México, 4 enero 1851. Para una síntesis de las posiciones liberales y conservadoras, véase O'Gorman, México, 1977, pp. 23-34. 
so, porque esto equivale a fomentar la holgazanería. ${ }^{36}$

Superficial, egoísta, enamorada de las nuevas doctrinas, tal èra, según los redactores de estos periódicos, la juventud mexicana. ${ }^{37}$ Las preocupaciones de la prensa católica no eran infundadas. No sólo eran los jóvenes el sector de la sociedad más dispuesto a abrazar las "revolucionarias" ideologías de moda, sino que las condiciones excepcionales de la primera época independiente habían empujado al "futuro de la nación" a desempeñar, quizá demasiado pronto, un papel central en el campo de la política. ${ }^{38}$ Según los redactores, la experiencia no era ya requisito para ocupar un cargo. El poder político era para

todos los que, encontrándose indignos de figurar en puestos de importancia bajo un orden de las cosas arreglado y estable, cifran sus esperanzas de mando y de poder en las revueltas y los trastornos de una sociedad desquiciada [...] aquellos en fin que en política están por la preponderancia demagógica, y en religión, por la anarquía de las conciencias. ${ }^{39}$

36 "Educación de la mujer. Cartas sobre la novela de A. Dumas, titulada 'La boca del infierno'", La Cruz, 24 julio 1857.

37 "Carácter especial de nuestra juventud. Su indiferencia religiosa", La Verdad Católica, 25 febrero 1854; El Católico, 27 septiembre 1845.

${ }^{38}$ Lorenzo de Zavala tenía 34 años cuando participó en el Congreso del Imperio, Lucas Alamán fue secretario de Relaciones de la República Federal a los 31. Santa Anna tenía 39 cuando ocupó por primera vez la presidencia. Ya en la época de la guerra de Reforma, Miguel Miramón fue presidente a los 27 años.

39 "El porvenir de México", El Universal, 13,
Después de más de 30 años de ser gobernados por regímenes cuyo idealismo y entusiasmo juvenil había servido de poco, los conservadores pedían un gobierno "de viejos", más consciente de la realidad, cuya prioridad sería el orden: "para gobernar se necesitan años [...] ¿creen vds que es un juego de muchachos el gobernar los pueblos?" 40

La prensa católica construye, como contrapeso de la imagen del joven liberal, atolondrado y pretencioso, su imagen de la mujer. ${ }^{41}$ Ella aparece como depositaria de las virtudes por las que suspiran los conservadores: serenidad, recato y, sobre todo, devoción religiosa. ${ }^{42}$ Por ello, la mujer debería ocupar un lugar central en la familia, y ser la principal responsable de la educación de los hijos. La prensa católica es una gran abogada de la educación de la mujer:

16 y 18 octubre 1850, en García Cantú, Antología, 1986, p. 277.

${ }^{40}$ El Católico, 27 septiembre 1845.

41 El enfrentamiento es a menudo directo. Una "anécdota" del Espectador describe una escena en una tertulia: "Un pretendido 'espíritu fuerte' amontonaba multitud de absurdos, en una conversación, para probar que no tenemos alma [...] Entonces nuestro sabio se acercó a una señorita que allí estaba presente, y con aire de triunfo le preguntó ¿qué pensaba de su des. preocupada filosofia? - Me parece muy bien señor... tanto que me ha hecho variar el concepto que tenía de vos. Confieso mi error; hasta ahora os había tenido por un hombre como todos; pero habéis probado con mucho talento que no sois más que una bestia", El Espectador de México, 17 mayo 1851. Véase El Especta. dor de México, 10 mayo 1851.

42 "Lucía y Ricardo"; "La limosna", El Espectador de México, 1 febrero 1851; 29 marzo 1851. 
La que está destinada a ser compañera del hombre y madre de sus hijos, bueno es que tenga esos conocimientos para amenizar el tiempo que a solas pasa con aquél, y que pueda contribuir a la educación del fruto de su unión. ${ }^{43}$

Además, la mujer no es sólo responsable de la educación moral de sus hijos, sino también de la de su esposo:

Adam no conocía todavía lo que era un delito, empezó AMANDO A DIOS, y después AMÓ a la MUjer. Ahora en medio de la corrupción que nos rodea, cuando la inocencia es casi una cosa desconocida, y cuando la indiferencia o la duda todo lo marchita y destruye, puede con buen éxito conducirse al hombre por un camino inverso: puede emplearse su AMOR A LA MUJER* como un medio poderoso para liegar al AMOR DE DIOS. ("Entendemos como "amor a la mujer" aquel sentimiento de aprecio noble y elevado, inseparable del más fino, delicado y profundo respeto. Y no sólo el amor a la esposa sino también el que profesamos a nuestras madres, a nuestras hermanas y a nuestras hijas.)

Esta visión de la mujer es novedosa. Para la mentalidad colonial $-\mathrm{y}$ los escritos del obispo Franciso Fabián y Fuero demuestran que la ilustración contribuyó poco para cambiar esta imagen- ${ }^{45}$ la mujer era una fuente de

43 "Merecido elogio a las Sritas. Solliers, por sus afanes en los adelantos del bello sexo", $L a$ Verdad Católica, 25 febrero 1854.

44 "Bello sexo", El Espectador de México, 4 enero 1851.

${ }^{45}$ Fabián y Fuero, Colección, 1770, sobre todo 30 abril 1767 . pecado. De débil carácter, estaba siempre dispuesta a arrastrar al hombre por las vías del mal, por lo que necesitaba de la guía de un hombre-padre, marido, consejero espiritual- para no caer en el vicio y la inmoralidad. Su presencia misma era un elemento perturbador, casi contaminante, como vemos en la anécdota que relata la señora Calderón de la Barca acerca de la virreina que insistió en visitar el convento de San Francisco. Después de su visita, se levantaron todas las piedras que habían sido "desecradas" por su paso. 46

Así, vemos cómo la mujer pasa de ser un ente de moral incierta, casi sucio, a convertirse en la garante de la moral familiar. Quizá la defensa de la religión católica, realizada por las mujeres mexicanas durante la intervención norteamericana (1847-1848), ${ }^{47}$ contribuyó a forjar esta nueva imagen. El rechazo enfático y público de la tolerancia religiosa por parte de muchas mujeres, ya a finales de los años cuarenta, pero sobre todo durante el debate del Congreso Constituyente de 1856, reforzó su nueva posición: la mujer se había convertido en la defensora de la religión, la aliada inquebrantable de la Iglesia. Una representación de mujeres morelianas ante el Congreso afirmaba que

en el protestantismo la suerte de la mujer corre pareja con los inventos y caprichos de los sectarios, que de ordinario son enemigos de la estabilidad del matrimonio y fáciles en menospreciar nues-

\footnotetext{
46 Calderón de la Barca, Life, 1970, p. 220.

47 Pacheco, Intervención, 1994, p. 31.
} 
tros derechos y dignidad. Sólo el catolicismo, dimanado de Dios [...] vuelve generosamente sobre los derechos y dignidad de la mujer. ${ }^{48}$

La mujer devota, buena madre y buena esposa, es enaltecida por la prensa católica. Si bien este concepto halagador de la mujer contrasta con las opiniones de algunos liberales que las consideraban asustadizas y volubles, ${ }^{49}$ no habría que exagerar la benevolencia de tal modelo. Una ojeada a los "Consejos a las casadas", publicados por La Cruz, demuestra qué tan asfixiante podía ser este "ideal" católico de la mujer:

Tus atenciones a (tu marido) deben ser continuas, mas no inoportunas, afectuosas, mas no afectadas...

Respeta sus faltas, cúbrelas con un velo; no las confieses a nadie, ni aun a los autores de tus dias...

En las dolencias del cuerpo no te acostumbres a quejas o lamentaciones, que no alivian al que padece, y molestan a los que lo asisten...

La amistad entre dos mujeres jóvenes... es uno de los vínculos más frágiles, más peligrosos y más imprudentes que pueden contraer los mortales...

No te acostumbres a aprender las doctrinas morales en ficciones y alego-

48 Martínez, Representaciones, 1954, p. 27. Cabe destacar que las mujeres que firmaban esas representaciones defendian intereses propios concretos: el matrimonio sacramental, la unidad religiosa de las familias, etc. Es dificil pensar que fueran únicamente resultado de la manipulación del clero.

49 Véase la intervención de Francisco Zarco durante el debate sobre la tolerancia religiosa de 1856, en González Calzada, Debates, 1972, p. 59 rías, y considera que el mejor uso que puedes hacer de tu razón es aplicarla al conocimiento de tus deberes... ${ }^{50}$

\section{RELIGIÓN Y SOCIEDAD}

Al catolicismo, y sólo al catolicismo, está reservado el librar a la generación actual del caos de anarquía, sedición, lucha sangrienta de partidos, prostitución, mala fe, lujo afeminado... El Católico, 30 agosto 1845

Para los católicos estudiados, sólo la religión podía salvar del desastre a la sociedad mexicana. La religión católica había "creado y civilizado" a las sociedades americanas, rescatándolas de los sangrientos cultos prehispánicos, ${ }^{51}$ y representaba el único vínculo social que se había mantenido entre la violencia y el desorden de la época independiente, y la catastrófica derrota frente a Estados Unidos. Sólo ella podía sacar a México del atolladero:

Al salir del laberinto de sus revoluciones, la nación mexicana se parece al navegante que, después de haber luchado largo tiempo con la tempestad, es arrojado a una playa, donde nada encuentra por lo pronto más que la vida... donde estamos aún abrazados de la tabla salvadora del naufragio. Esta tabla son los principios conservadores

50 "Consejos a las casadas", La Cruz, 27 noviembre $1856 ; 14$ diciembre 1856.

51 "El catolicismo en América", La Cruz, 27 diciembre 1855. Representación al Soberano Congreso Constituyente, junio 29, 1856, en García Cantú, Antología, 1986, p. 392. 
que profesaron nuestros padres; en ellos está cifrada la paz y nuestra dicha... ${ }^{52}$

La religión aparece en estos artículos como lo único que había mantenido vivos algunos de los principios que impedían la disgregación total de la sociedad, como la caridad y la unidad religiosa. ${ }^{53}$ Esta percepción no estaba del todo mal fundada. La Iglesia era la principal institución que se ocupaba de la beneficencia (el Estado no tenía la capacidad financiera). ${ }^{54}$ Después de presenciar algunos de los gestos de la filantropía mexicana, Frances Calderón de la Barca afirmaba que en ningún país del mundo se practicaba la caridad a una escala tan noble como en México, y que ésta era el "atributo distintivo de un país católico". ${ }^{55}$ La religión representaba un elemento integrador para la población: el culto reunía a fieles de todos los estratos sociales (aunque no en una posición de igualdad), ${ }^{56}$ y las fiestas religiosas marcaban la pauta de la vida cotidiana. ${ }^{57}$ Un cierto "sentimiento católico", dificil de describir y que se manifestaba seguramente de distintas formas, pre-

52 "Recursos de México", La Verdad Católica, 4 marzo 1854 .

53 "La caridad en México", La Verdad Cató lica, 20 mayo 1854.

54 "Protesta del obispo Juan Cayetano de Michoacán", El Católico, 30 enero 1847. También véase el editorial del 23 de enero.

55 Calderón de la Barca, Life, 1970, p. 285.

56 Véase el contraste con las iglesias "elitistas" del mundo anglosajón, que describe Calderón de la Barca. Calderón de la Barca, Life, 1970, p. 369. Véase también la intervención de Mariano Arizcoreta en González Calzada, Debates, 1972 , p. 84 .

${ }^{57}$ Prieto, Memorias, 1958, p. 21. valecía en la mayor parte de la sociedad (si excluimos a los muy pocos liberales que se decían irreligiosos, como Ignacio Ramírez). Vislumbramos este sentimiento en el anticlerical Guillermo Prieto, cuando relata que el ideal de los niños de su época (y suponemos que de él también) era "ser emperador, santo sacerdote, o, cuando muy menos, mártir del Japón", ${ }^{58}$ y en la resistencia de los 400 barreteros contratados para demoler los edificios del Convento de San Francisco para comunicar el callejón de Dolores y San Juan de Letrán en $1856 . .^{9}$ Los conservadores compartían con la señora Calderón de la Barca la opinión de que la religión católica era, en México, el único freno a los excesos tanto de ricos como de pobres. ${ }^{60}$

Para los conservadores, la salvación del país dependía de que se restableciera la religión en un lugar central en la vida pública, y sobre todo en la educación. Según ellos, la juventud, vanidosa y "afeminada", ${ }^{61}$ se hallaba en tan deplorable estado por falta de instrucción religiosa. ${ }^{62}$ Olvidando quizá que muchos liberales prominentes - como por ejemplo José María Luis Mora y

58 Ibid., p. 24

59 García Cubas, Libro, 1950, pp. 112-113.

${ }^{60}$ Calderón de la Barca, Life, 1970 , p. 164.

61 "Carácter especial de nuestra juventud. Su indiferencia religiosa", La Verdad Católica, 25 febrero 1854.

62 Munguía, en García Alcaraz, Cuna, 1971, pp. 458-461; Alamán, Historia, 1938, vol. III, pp. 450-451; "A nuestros suscriptores", La Cruz, 13 marzo 1856; El Católico, 6 marzo 1847; "La enseñanza pública", El Espectador de México, 15 marzo 1851; "Distribución de premios en el establecimiento de Doña Joaquina Besares de Músquiz...", La Verdad Católica, 29 abril 1854. 
Lorenzo de Zavala - habían sido educados en un seminario, estos hombres consideraban que la educación religiosa, al sentar una base moral para el conocimiento, formando "un pacto feliz entre los sentidos, la imaginación y la piedad", ${ }^{63}$ sería una especie de "vacuna" en contra de ese "filosofismo, [...] comparado con tanta exactitud al cólera morbo, que $[\ldots]$ ha devastado a todo el globo". ${ }^{64}$ La prensa católica clamaba por una instrucción religiosa sólida y universal, impartida tanto a los niños de las clases altas como a los de los artesanos. ${ }^{65}$ A veces, el tono de los artículos es casi paranoico:

Es preciso que la sabiduría tenga por base el conocimiento de Dios, y esto no se adquiere sino por el estudio de la religión [...] Reiráse de esto la juventud corrompida que se arrastra en el cieno inmundo de los vicios y la prostitución; mas nuestras reflexiones serán dignas [...] de las personas sensatas que ven en cada uno de los preceptos de la religión las disposiciones más a propósito para contener al hombre en la senda de los vicios y conducirle por la virtud. ${ }^{66}$

¿Por qué la urgencia de la demanda? Porque los conservadores se daban cuenta de que el problema iba más allá de una instrucción religiosa deficiente. "El siglo diez y nueve, siglo de intereses materiales y de indiferencia re-

${ }^{63}$ Munguía, en García Alcaraz, Cuna, 1971, p. 461 .

64 "La enseñanza pública", El Espectador de México, 15 marzo 1851.

${ }^{65}$ La Verdad Católica, 24 diciembre 1853.

66 "Carácter especial de nuestra juventud. Su indiferencia religiosa", La Verdad Católica, 25 febrero 1854 . ligiosa", ${ }^{67}$ había afectado lo que había sido el gran edificio de la religiosidad novohispana. Tanto para los conservadores como para los liberales, la Iglesia era la única institución que disponía de la liquidez financiera para poder extender créditos al Estado; la única otra fuente, seguían siendo los agiotistas quienes cobraban un interés de, por lo menos, $24 \%$ mensual. ${ }^{68}$ Pero, mientras los conservadores estaban conscientes de la eficiencia de la economía eclesiástica, ${ }^{69}$ los liberales responsabilizaban a la concentración de propiedades en manos de la Iglesia de la ausencia de pequeños propietarios y del estancamiento económico del país. ${ }^{70} \mathrm{Los}$ sucesivos ataques en contra de los bienes eclesiásticos y de la autoridad moral del clero habían empujado a la Iglesia hacia una posición defensiva y ultramontana..$^{71}$ La autoridad civil, desde finales del siglo XVII, había desplazado progresivamente a la religiosa, tratando de crear una esfera separada -y reducida- para lo espiritual. Con la secularización habían disminuido la caridad cristiana, el esplendor del culto, las vocaciones, ${ }^{72}$ la devoción popular:

67 "Controversia: sobre la tolerancia civil de cultos en México", La Cruz, 24 julio 1856.

68 Bazant, Altenation, 1971 , pp. 3-6.

${ }^{69}$ Ibid., p. 287; Ruiz, Prensa, 1959, pp. 74. 75.

${ }^{70}$ El Católico atacó violentamente el decreto de nacionalización y venta de bienes eclesiásticos de Valentín Gómez Farías (11 enero 1847). $16,23,30$ enero $1847 ; 6,13,20,27$ febrero 1847. Pero los hacendados conservadores, quizá a su pesar, ideológicamente favorecían la nacionalización, que hubiera cancelado sus deudas con la Iglesia. Bazant, Alienation, 1971, p. 7.

${ }^{71}$ Meyer, Historia, 1991, pp. 69-82.

72 "Noticias religiosas nacionales", La Cruz, 5 junio 1856. 
Notamos, con sentimiento, que estas santas rogativas se miran con indiferen$c i a, y$ apenas hay personas piadosas que asistan a una costumbre tan antigua $y$ venerable. Después nos quejamos de que Dios nos aflige con tempestades, heladas, terremotos y otras plagas. Hagamos públicas oraciones, y Dios bendecirá nuestro campo. ${ }^{73}$

La posición de los conservadores era francamente incómoda: por un lado, afirmaban que sólo la religión tenía la fuerza moral para salvar al país; por otro, admitían que lo que debía ser la "piedra clave" de la reconstrucción nacional ${ }^{74}$ se hallaba en un estado tan vulnerable que era imprescindible protegerla. Esta actitud algo paranoica traducía quizá las tensiones internas de un grupo conservador donde ciertos miembros, seducidos por el progreso material de la "modernidad", empezaban a ver a la Iglesia y a la religión como un obstáculo en el camino hacia la prosperidad. El caso más obvio es quizá el de Esteban de Antuñano, defensor de las propiedades eclesiásticas y de la legitimidad del diezmo en los años treinta, y, en los cuarenta, promotor no sólo de la desamortización de bienes de manos muertas - cuyo capital podría entonces financiar proyectos de industrialización- sino de la clausura de las escuelas de teología y de la abolición de las órdenes religiosas masculinas. ${ }^{75}$ En la prensa católica, los debates sobre el progreso material de los países protestantes y el

\footnotetext{
1846.

73 "Gacetilla devota", El Católico, 18 abril

74 Velasco, Guerra, 1975, p. 155.

${ }^{75}$ Hale, Alamán, 1961, pp. 238-239.
}

debate sobre Ia tolerancia de cultos reflejaban estas tensiones, lo que explica la posición ambigua de estos periódicos frente al progreso material. Es en este punto donde la ideología conservadora es menos consistente. Los periódicos católicos reclamaban caminos, industria, seguridad y población: México debía participar de los adelantos del siglo. Desafortunadamente, se lamentaban los artículos periodísticos, "las sociedades [...] impulsadas de un movimiento que pasma, $[\ldots]$ las que llaman la atencion por su comercio y sus adelantos", eran precisamente "donde menos tiene su culto la religión católica" ${ }^{76}$ Por consiguiente, continuaban estos artículos, esos países vivían una falsa prosperidad, pues el bienestar material no estaba basado en un bienestar espiritual:

¿Qué es de esa felicidad de las sociedades que despreciando lo que exige la religion y la moral, se engrandecen a costa de mil víctimas sacrificadas a su orgullo? La experiencia responderí: nosotros, fundados en ella, no podemos menos que manifestar que si el culto por el cual se manifiestan las criaturas reconocidas a su creador no se aumenta, las sociedades marcharán a su prosperidad aparente para sepultarse en un profundo olvido. ${ }^{77}$

Para los conservadores era un tanto vergonzoso que los países más modernos y desarrollados fueran países protestantes, pero querían pensar que los dos fenómenos no estaban ligados.

${ }^{76}$ La Verdad Católica, 14 enero 1854.

77 Ibid. Véase también "Los países católicos y los países protestantes", La Cruz, 3 enero 1856. 


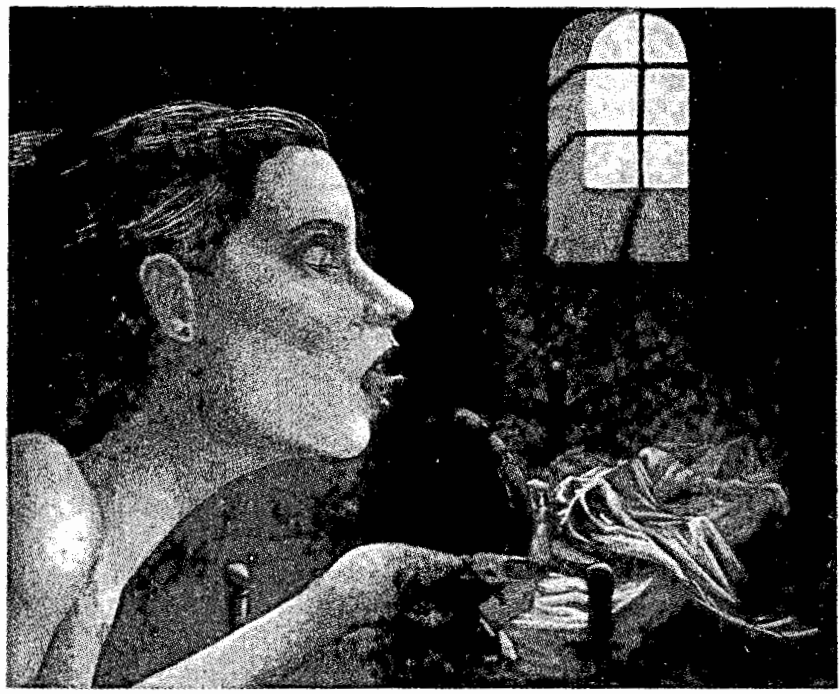

Querían mantener los valores tradicionales; de la modernidad no querían más que la prosperidad material. ${ }^{78}$ Además, en México no podía haber progreso si no se mantenía la unidad religiosa, que era el único lazo de unión que había sobrevivido al desastre de las primeras tres décadas de vida independiente. Para los liberales, por el contrario, la Iglesia y la religión eran directamente responsables del atraso de México. ${ }^{79}$

Estas diferencias irreconciliables sentaron el tono del debate sobre la libertad de cultos, que culminó en 1856, y que representa, según algunos autores, la "lucha ideológica más in-

${ }^{78}$ O'Gorman, México, 1977 , p. 32.

${ }^{79}$ Meyer, Historia, 1991, p. 64. tensa" de la historia nacional. ${ }^{80}$ Para los liberales, la separación de la Iglesia y el Estado y la libertad de conciencia eran principios ideológicos importantes. Pero estaban conscientes de la impopularidad de tales medidas, cuya promulgación sería percibida como una agresión a la Iglesia y a la religión. Por ello la libertad de cultos era presentada por la mayoría de los liberales -exceptuando, una vez más, a los "puros", que eran abiertamente antireligiosos-81 como un "mal necesario" para impulsar la inmigración. ${ }^{82}$

${ }^{80}$ Ruiz, Prensa, 1959, p. 38; Martínez, Re. presentaciones, 1959 , p. 5.

${ }^{81}$ Véanse, por ejemplo, las intervenciones de Francisco Zarco y Guillermo Prieto en González Calzada, Debates, 1972, pp. 53, 75.

${ }^{82}$ Berninger, Inmigración, 1974, p. 117. 
Los liberales miraban con envidia el éxito económico y comercial de los estadounidenses, y afirmaban que éste provenía del importante flujo migratorio que, según ellos, era resultado de la libertad de cultos que prevalecía en Estados Unidos. Los conservadores abogaban también por la inmigración, pero pensaban que los nuevos colonos tenían que ser católicos para poder ser integrados a la sociedad mexicana. Los liberales consideraban que los inmigrantes católicos, españoles o italianos, no harían más que reforzar una "tradición cultural" anacrónica. ${ }^{83}$ Ya en los años treinta, Vicente Rocafuerte afirmaba que el inmigrante protestante èra más deseable que el católico: era más trabajador, más industrioso y hasta más limpio. ${ }^{84}$ Para los conservadores, nada era más peligroso que la infiltración del protestantismo:

El protestantismo ha matado toda autoridad sobre la tierra, desconociendo la autoridad religiosa. ¿Cómo han de respetar los pueblos a las autoridades que mandan en nombre de leyes temporales, cuando se les enseña que son dueños de sí mismos en lo que toca a las leyes eternas?

Sin duda, los conservadores miraban la cuestión de la inmigración con ojos más realistas que los liberales. ${ }^{86}$

${ }^{83}$ Ibid., p. 187.

${ }^{84}$ Rocafuerte, Ensayos, 1831, p. 17.

85 "Controversia: el catolicismo y las revolu. ciones modernas", La Cruz, 6 diciembre 1855. Véanse "El protestantismo", El Católico, 12 septiembre 1846; "Prospecto", El Espectador de Méxtco, 4 enero 1851 .

${ }^{86}$ Berninger, Inmigración, 1974, p. 187.
Los liberales pretendían que la libertad de cultos era la "piedra filosofal" mediante la cual se conseguía hasta "la cuadratura del círculo". ${ }^{87}$ Los conservadores comprendían que México no sería un foco de inmigración hasta que tuviera "paz, justicia y buen gobierno", hasta que pudiera dar "garantías de orden y seguridad a las naciones" 88 Además, la inmigración protestante no significaría más que la introducción de otro elemento de discordia. Al mismo tiempo que proclamaban que la religión católica era el vínculo más fuerte de la sociedad mexicana, los conservadores se mostraron mucho menos convencidos que los liberales de su capacidad para resistir la "contaminación" de las sectas protestantes. ${ }^{89}$ El catolicismo no podía resistir por sí solo, había que protegerlo, y esto había de lograrse mediante una religión de Estado y la intolerancia de cultos.

En la concepción conservadora del poder político, Iglesia y Estado debían actuar conjuntamente para hacer "la felicidad del pueblo que la Providencia les confia". ${ }^{90}$ Los gobiernos de la primera mitad del siglo XIX disponían de una autoridad limitadísima, mien-

${ }^{87}$ Impugnación, 1832, p. 9.

${ }^{88}$ Marcelino Castañeda, en González Calzada, Debates, 1972, p. 15: La disponibilidad de mano de obra indigena, uno de los factores que debió ser determinante para disuadir la inmigración a México, no es mencionado por ninguno de los dos partidos. Sánchez, Población, 1975, p. 175.

${ }^{89}$ Véanse las intervenciones de José María Mata y José María Castillo Velasco en González Calzada, Debates, 1972, pp. 29; 47.49.

90 José Joaquín Herrera, presidente de México entre junio de 1848 y enero de 1851 , citado por González Avelar, México, 1971, p. 75. 
tras la Iglesia mantenía aún gran parte de la suya. ${ }^{91}$ El pueblo mexicano carecía de lo que se llamaría hoy "espíritu cívico", y sólo cobraban fuerza para frenar las tendencias delictuosas de los hombres las sanciones religiosas: "Los gobiernos tienen que profesar y proteger alguna religión, porque tienen que cumplir y hacer cumplir derechos y obligaciones que están estrechamente ligados con la religión". ${ }^{92} \mathrm{EI}$ gobierno debía reflejar y fortalecer la unidad moral y religiosa de la nación: un gobierno ateo, "viva reproducción del infierno", 93 no podía más que "introducir, en los pueblos que tengan la desgracia de sufrirlo, un ateísmo práctico que [...] debilitaría los lazos de la sociedad, y acabaría por relajarla, disolverla y consumirla". ${ }^{94}$

El catolicismo tenía entonces que ser la religión de Estado. Pero también se tenían que tomar medidas para que se mantuviera como la única religión. El gran temor de los conservadores era que, con la imposición de la libertad de cultos, se extendiera el protestante. Al parecer, la población mexicana era demasiado ignorante o demasiado inocente ${ }^{95}$ para poder resistir a la tentación de las "prácticas fáciles

${ }^{91}$ Meyer, Historia, 1991, p. 64.

92 La Cruz, 24 enero 1856. José María Luis Mora también consideraba que éste era un gran problema para la formación de la, República. Mora, Obras, 1987, vol. 4, p. 298.

93 El Católico, 30 agosto 1845.

94 "Breve refutación de las principales razo. nes con que se ha sostenido la libertad de cultos en el Congreso General", La Cruz, 14 agosto 1856.

95 Prisciliano Díaz González, en González Calzada, Debates, 1972, p. 106. del protestantismo",96 que, además, parecía prometer un futuro mejor:

El protestantismo es la reunión de todos los errores [...] porque [...] brinda en lo pronto con los medios de hacer fortuna, manteniendo una apariencia de fe y de culto [...] se presenta con los medios más eficaces para seducir a los incautos, que los que tiene la credulidad descubierta. Lisonjea en primer lugar a la multitud con las falaces promesas de una quimérica libertad [...] Lisonjea en segundo lugar a la ambición [...] por último, a las pasiones [quitándoles] el molesto yugo de los sacramentos y la disciplina religiosa. ${ }^{97}$

Además, afirmaban los católicos, no sin algo de razón, los inmigrantes protestantes eran poco confiables. En abierto desafio a las leyes de inmigración mexicanas, los misioneros protestantes se introducían al país disfrazados de "médicos o curanderos", dispuestos a "corromper los corazones de la juventud" mediante biblias y novelas francesas. ${ }^{98}$ Lo que los hacía aún más peligrosos es que no podía esperarse que desarrollaran sentimientos patrióticos hacia el país que los había recibido, como bien lo demos. traban los sucesos en Texas. ${ }^{99}$ Desde la independencia, México se había de-

${ }^{96}$ Marcelino Castañeda, en González Calz:lda, Debates, 1972, p. 12.

97 "Controversia: ataques dirigidos a la religión", La Cruz, 8 mayo 1856.

98 "Circular del gobierno eclesiástico del arzobispado de México", La Verdad Católica, 4 marzo 1854.

99 Antonio Aguado, en González Calzada, Debates, 1972, p. 190. Trejo, Consideraciones, 1990, p. 56. 
finido como un país católico, y la resistencia a la invasión estadounidense había sido interpretada como una "cruzada" para defender la religión católica frente a la impiedad del vecino del norte. ${ }^{100}$ Joel Poinsett, primer embajador de Estados Unidos en México, escribía al enviado de su gobierno en Gran Bretaña que su misión era "extender los principios liberales del comercio, para la protección mutua de nuestra industria y capital y para la difusión de sentimientos religiosos más tolerantes". ${ }^{101} \mathrm{El}$ hecho de que la política expansionista de Estados Unidos estuviera teñida con ese tipo de "espíritu misionero" no podía más que polarizar la situación. Para la prensa católica, la derrota frente al coloso del norte reforzaba la percepción de que una "frontera católica" era imprescindible para prevenir que las ambiciones de Estados Unidos arrasaran con México. ${ }^{102}$

\section{CONCLUSIÓN}

Para muchos conservadores, la religión católica debía ser el elemento central de la regeneración de México. Sin unidad religiosa, el país caería en la disolución y sería totalmente sometido a Estados Unidos. En un artículo sobre Miguel Miramón, Patricia Galeana afirma que "el propio sentimiento na-

${ }^{100}$ Velasco, Guerra, 1975, pp. 78, 128.

101 Poinsett a Rufus King, 10 de octubre, 1825, citado en Trejo, Consideraciones, 1990 , p. 50 .

102 "Relaciones entre Estados Unidos y México", La Verdad Católica, 25 febrero 1854. cional estaba para los conservadores aun por debajo del sentimiento religioso" ${ }^{103}$ La lectura de los periódicos católicos indica que la relación entre los conservadores y el catolicismo era más compleja: no estaba subordinado el sentimiento nacional al religioso, sino que estaban estrechamente ligados, y eran dependientes el uno del otro. Los conservadores identificaban al catolicismo con la mexicanidad; para ellos el patriotismo era inseparable del sentimiento religioso. Su posición era irreconciliable con la separación de la Iglesia y el Estado que proponían los liberales. Los conservadores no eran meros instrumentos de un clero que se sentía acorralado, y no se lanzaron a la guerra de Reforma simplemente por retrógrados. ${ }^{104} \mathrm{La}$ religión representaba una parte íntegra - si no es que central- de su proyecto de nación. Durante el debate político de la

103 Galeana, Conservadores, 1991, p. 87.

${ }^{104} \mathrm{Si}$ suponemos que el objetivo principal del clero era mantener sus privilegios tanto económicos como sociales, es interesante, por ejemplo, que si bien el primer acto de gobierno de Félix Zuloaga en enero de 1858 fue la de. rogación de la ley de desamortización, no lo hizo sino hasta que la Iglesia prometiera prestarle un millón y medio de pesos. En agosto de 1860, Miguel Miramón se vio forzado a confiscar la plata, el oro y las joyas de las iglesias (con excepción de los vasos sagrados). Ya en agosto de 1857, el periódico conservador El Ttempo manifestaba que, a pesar de haber sido nocivas, las adjudicaciones efectuadas bajo los auspicios de la Ley Lerdo debían considerarse como un fait accompli, y ser sancionadas por un concordato. Como vemos, la relación clero-iaicos conservadores no era una relación de simple manipulación y dominio por parte de la jerarquía eclesiástica. Bazant, Alienation, 1971, pp. 135, 136-137, 174. 
década de 1850 , las propuestas liberales para reformar la propiedad eclesiástica, los fueros, el matrimonio y la educación pública fueron percibidas como un ataque directo a la Iglesia y al catolicismo. La guerra de Reforma representaba para los conservadores no sólo la protección de la religión, sino la defensa del futuro de México.

Después de la derrota ${ }^{105}$ del conservadurismo como opción política, muchos de los conservadores católicos sostuvieron una ideología coherente de tradicionalismo político, volcada, durante el porfiriato, a la acción social y educativa. A través de publicaciones -durante años apolíticas- como La Voz de México y La Sociedad Católi$\mathrm{ca}$, e instituciones académicas como la Escuela Católica de Jurisprudencia y la Sociedad Literaria Munguía, difundieron los principios de ley natural, orden social moral y libertad limitada. ${ }^{106}$ Su falta de compromisos con el régimen en vigor les permitió desarrollar una actitud crítica -casi excepcional en la época- hacia el gobierno y sus acciones. Centrados en problemas sociales como la desmoralización y la pobreza, fueron los primeros en percibir que el gobierno de Díaz se perfilaba como dictadura y que la desamorti-

105 Habría que matizar este término. Durante el porfiriato, con la consolidación del "conservadurismo liberal", asistimos no sólo al renacimiento de ciertos principios "conservadores" (como "democracia dirigida" y Senado), sino a la conciliación -aunque informal- del Estado y la Iglesia. Case, Resurgimiento, 1975; Adame, Pensamiento, 1981, pp. 103, 114; Noriega, Pensamiento, 1972 , p. 458. 120 .

106 Adame, Pensamiento, 1981, pp. 118 - zación había acelerado la concentración de riqueza y agudizado la pauperización. ${ }^{107}$ El pensamiento conservador católico, adaptándose a nuevas circunstancias donde las oportunidades de acción política para un "partido conservador" estaban muy limitadas, sostuvo, adaptó y reelaboró muchos de los principios por los que habían luchado los conservadores decimonónicos, al mantener como objetivo principal la construcción de la sociedad nacional sobre los principios morales establecidos por el catolicismo. Así, aunque se le supone escandalosamente vencido después de 1867 , el conservadurismo, a principios del siglo $\mathrm{XX}$, seguía siendo un elemento dinámico dentro del pensamiento social y político mexicano.

\section{Biblografía}

-Adame Goddard, Jorge, $E l$ pensamiento político y social de los católicos mexicanos, 1867-1914, Universidad Nacional Autónoma de México, México, 1981.

-Alamán, Lucas, Historia de México, Publicaciones Herrerías; México, 1938, 3 . volúmenes.

-Bazant, Jan, Alienation of Church wealth in Mexico: Social and economic aspects of the liberal revolution, 18561875. Cambridge University Press, Cambridge, 1971. , Antonio Haro y Tamariz y sus aventuras políticas, 1811-1869, El Colegio de México, México, 1985.

-Berninger, Dieter George, La inmigración en México, 1821-1857. Secretaría de Educación Pública, México, 1974.

-Case, Robert, "Resurgimiento de los 107 Ibid., 1981, pp. 72-108. 


\section{SECUENCIA}

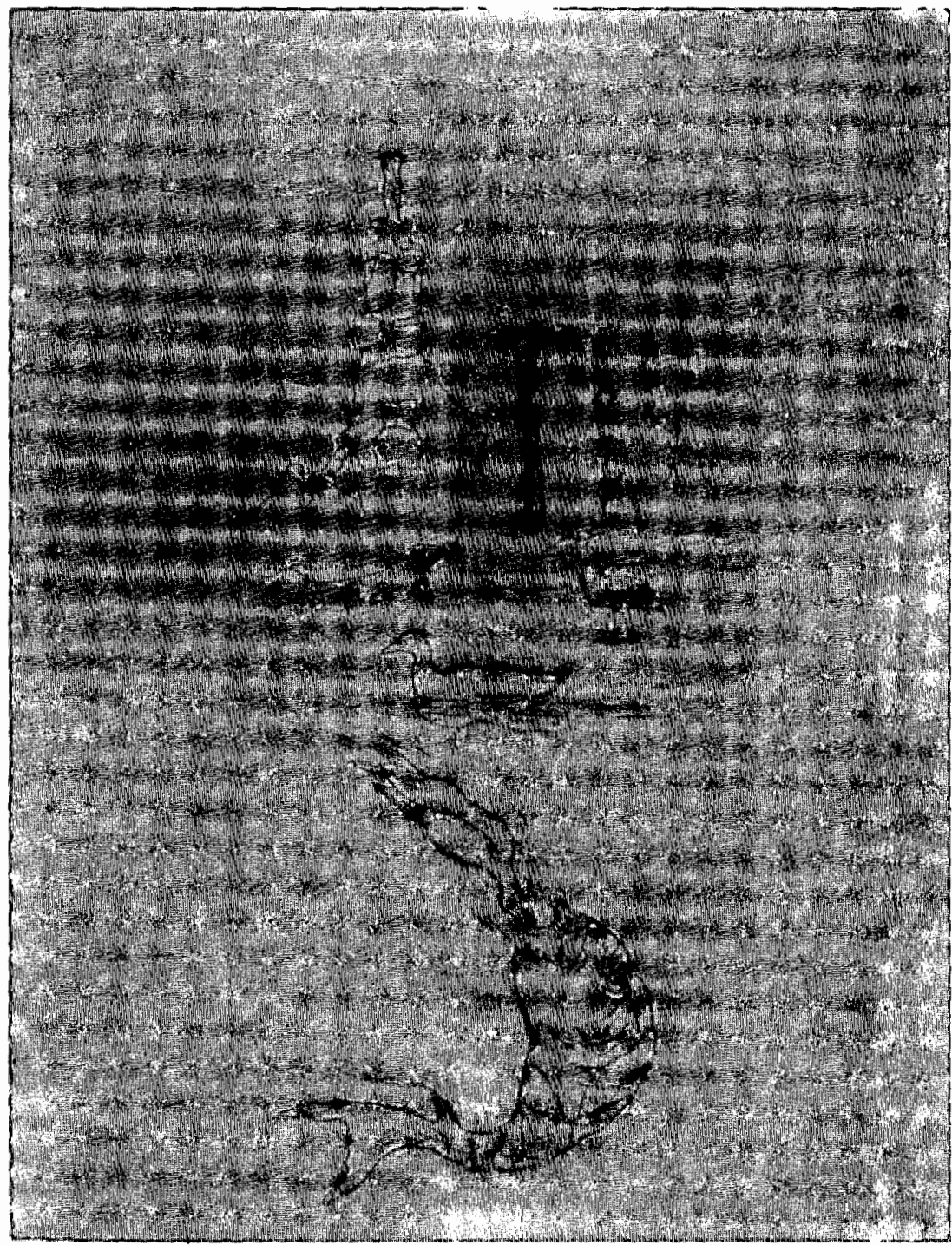


conservadores en México 1876-1877", Historia Mexicana, vol. xx, núm. 2.

-Calderón de la Barca, Frances, Life in Mexico. The letters of Fanny Calderón de la Barca, with new materials from the author's private journals. Edited and annotated by Howard T. Fisher and Marion Hall Fisher, Anchor Book, Doubleday and Company, Garden City, Nueva York, 1970.

-Fabián y Fuero, Francisco, Colección de providenctas diocesanas del obispo de Puebla de los Ángeles, hechas y ordenadas por su señoría ilustrísima..., Imprenta del Real Seminario Palafoxiano, Puebla, 1770.

-Galeana, Patricia, "Los conservadores en el poder: Miramón", Estudios de Historia Moderna y Contemporánea de México, vol. XIV.

-García Alcaraz, Agustín, La cuna ideológica de la Independencia, Fimax Publicistas, Morelia, 1971 (Colección Bicentenario).

-García Cantú, Gastón, Antología. El pensamiento de la reacción mexicana, Tomo I (1810-1859), Universidad Nacional Autónoma de México, México, 1986, 2 volúmenes.

-García Cubas, Antonio, El libro de mis recuerdos. Narraciones históricas, anecdóticas y de costumbres mexicanas anteriores al actual estado social, Editorial Patria, México, 1950.

-González Avelar, Miguel, México en el umbral de la Reforma, Federación Editorial Mexicana, México, 1950.

-González Calzada, Manuel, Los debates sobre la libertad de creencias, Cámara de Diputados, XLVIII Legislatura del $\mathbf{H}$. Congreso de la Unión, México, 1972.

-Hale, Charles A., Mexican liberalism in the age of Mora, 1821-1853, Yale University Press, New Haven, Londres, 1968. , "Alamán, Antuñano y la continuidad del liberalismo", Historia Mexicana, vol. XI, núm. 2.
-Iglesias, José Maria, Revistas históricas sobre la intervención francesa en México, Imprenta del Gobierno, en Palacio, México, 1868, 3 volúmenes.

-Impugnación a la nueva secta sublimes cristianos, contenida en el ensayo sobre tolerancia religiosa del ciudadano Vicente Rocafuerte, Imprenta de Rivera, México, 1832.

-Lira, Andrés, Espejo de discordias. La sociedad mexicana vista por Lorenzo de Zavala, José María Luis Mora y Lucas Alamán, Secretaría de Educación Pública, México, 1984 (Cien de México).

-Martínez Báez, Antonio, Representactones sobre la tolerancia religiosa, México, 1959 (Col. Siglo XIX, 4).

-Mc Gowan, Gerald L., Prensa y poder, 1854-1857. La revolución de Ayutla. El Congreso Constituyente, El Colegio de México, México, 1978.

-Meyer, Jean, Historia de los cristianos en América Latina. Siglos $X I X$ y XX, Editorial Vuelta, México, 1991.

- Mora, José María Luis, El clero, el Estado y la economía nacional. Empresas editoriales, México, 1950.

, Obras Completas, Instituto Mora/Secretaría de Educación Pública, México, 1986-1987, 8 tomos.

-Noriega, Alfonso, El pensamiento con: servador y el conservadurismo mexicano, Universidad Nacional Autónoma de México, México, 1972, 2 tomos.

-O'Gorman, Edmundo, México. El trauma de su historia, Universidad Nacional Autónoma de México, México, 1977.

-Pacheco, María Antonieta, "La intervención norteamericana y la tolerancia religiosa", mecanografiado, 1994.

-Planes en la nación mexicana. $11 \mathrm{li}$ bros. Cámara de Senadores, república mexicana, LIII Legislatura, México, 1987.

-Prieto, Guillermo, Memorias de mis ttempos, Editorial Patria, México, 1958.

-Rocafuerte, Vicente, Ensayos sobre la tolerancia religiosa por el C. Vicente Ro- 
cafuerte, Imprenta de Rivera, México, 1831.

-Ruiz Castañeda, María del Carmen, La prensa periódica en torno a la Constitución de 1857, Universidad Nacional Autónoma de México, México, 1959.

-Sordo Cedeño, Reynaldo, El Congreso en la primera república centralista, $\mathrm{El}$ Colegio de México/Instituto Tecnológico Autónomo de México, México 1993.

-Trejo, Evelia, "Consideraciones sobre el factor religioso en la pérdida del territorio de Texas, 1821-1835", Estudios de His. toria Modernay Contemporánea de México, vol. XIII.

-Sánchez Albornoz, Nicolás, La población de América Latina. Desde los tiempos precolombinos al año 2000, Alianza Editorial, Madrid, 1973.

-Velasco, Jesús, La guerra del 47 y la opinión pública (1845-1848), Secretaría de Eđucación Pública, México, 1975.

\section{HeMEROGRAFIA}

- El Católico. Periódico Religioso, PolíticoCristiano, Científico y Literario. Dedicado especialmente al Ilmo. Señor Dr. Don Manuel Posada y Garduño, Arzobispo de México, impreso por R. Rafael en la Oficina del Católico, calle de la Cadena, núm. 13, México, 1845-1847.

-El Espectador de México. Revista Semanal de Religión, Ciencias, Literaturay Bellas Artes, publicada por los redactores del Untversal y del antiguo Observador Católico, México, 1851-1852.

- La Verdad Católica, México, 18541855.

-La Cruz. Periódico exclusivamente religioso, establecido para difundir las doctrinas ortodoxas $y$ vindicarlas de los errores dominantes, México, 1855. 1857. 